\title{
ANALISIS PENCEMARAN PERAIRAN PESISIR BEDUKANG, DESA DENIANG, KABUPATEN BANGKA
}

\section{ANALYSIS POLLUTION OF COASTAL WATER IN BEDUKANG, DENIANG VILLAGE, BANGKA REGENCY}

\author{
Dareen Nadya Rema ${ }^{1}$, Kurniawan ${ }^{1}$ dan Umroh ${ }^{2 *}$ \\ ${ }^{1}$ Program Studi Manajemen Sumberdaya Perairan, Fakultas Pertanian Perikanan dan Biologi, \\ Universitas Bangka Belitung \\ ${ }^{2}$ Program Studi IImu Kelautan, Fakultas Pertanian Perikanan dan Biologi, \\ Universitas Bangka Belitung \\ Kampus Terpadu UBB, Gedung Teladan, Desa Balunijuk, Bangka, \\ Kepulauan Bangka Belitung, 33172 Indonesia
}

Email: umrohque@gmail.com

\begin{abstract}
ABSTRAK
Perairan pesisir Bedukang masuk ke dalam wilayah Kecamatan Riau Silip Kabupaten Bangka. Perairan pesisir Bedukang terdapat aktifitas penambangan timah dan peternakan yang secara langsung ataupun tidak langsung memberikan tekanan yang signifikan terhadap kualitas perairan di wilayah tersebut. Tujuan penelitian ini adalah menganalisis karakteristik kualitas perairan pesisir Bedukang serta mengkaji tingkat pencemaran di perairan pesisir Bedukang dengan menggunakan Indeks Pencemaran (IP). Parameter yang diukur secara insitu yaitu parameter suhu, $\mathrm{pH}$, serta salinitas sedangkan parameter yang diukur secara exsitu yaitu TSS, TDS, BOD, Logam Pb dan Total Coliform. Hasilnya analisis Indeks Pencemaran menunjukkan bahwa pada pada stasiun 1, stasiun 3 dan stasiun 4 termasuk kategori tercemar ringan dengan nilai masing-masing nilai 2,819, 1,025 dan 1,022. Pada stasiun 2 termasuk kategori mutu perairan baik dengan nilai indeks pencemarannya 0,919.
\end{abstract}

Kata kunci : Indeks Pencemaran, Kualitas Air, Sedimen, Perairan Pesisir Bedukang

\begin{abstract}
Administratively Bedukang coastal waters get into the District of Riau Silip Bangka. There is a tin mining activities and farms in the region that directly or indirectly provide significant pressure on water quality in the region. The purpose of this study was to analyze the characteristics of the quality of coastal waters Bedukang and assess the degree of pollution in coastal waters Bedukang using Pollution Index (IP). Parameters measured insituely are temperature, $\mathrm{pH}$, and salinity while the parameters measured exsually are TSS, TDS, BOD, Metals $\mathrm{Pb}$ and Total Coliform. The result of the Pollution Index analysis shows at the first station, the station 3 and the station 4, including lightly polluted category with the value of each value of $2.819,1.025$ and 1.022 . At station 2 including good water quality category with the pollution index value of 0.919 .
\end{abstract}

Keywords : Pollution Index, Quality of Water, Sediment, Coastal Water Bedukang

\section{PENDAHULUAN}

Perairan pesisir Bedukang merupakan salah satu wilayah pesisir di daerah utara Bangka. Perairan ini termasuk wilayah Kecamatan Riau Silip, Kabupaten Bangka. Daerah pesisir Bedukang memiliki aliran sungai yang bermuara pada perairan pantai Bedukang. Sungai tersebut dapat mempengaruhi secara langsung maupun tidak langsung terhadap kualitas air di perairan pesisir Bedukang. Sungai tersebut merupakan aliran pembuangan yang banyak membawa bahan buangan dari berbagai aktivitas, seperti aktivitas peternakan babi dan pertambangan. Daerah pesisir Bedukang merupakan salah satu daerah yang aktif dalam aktivitas penambangan timah. Limbah yang dihasilkan dari aktivitas tersebut dinamakan tailing yang mengalir dari perairan Sungai Bedukang. Tailing tersebut berpotensi menyebabkan pencemaran di perairan pesisir Bedukang. Tailing mengandung bahan-bahan seperti Zirkon, 
Uranium, Korundum dan logam timbal (Suprapto, 2008).

Pencemaran sungai dapat berasal dari faktor alam, limbah domestik (limbah dari perumahan, perkantoran, dan peternakan) dan limbah industri yang dapat terbawa dan terakumulasi sampai ke muara serta menyebabkan pencemaran lingkungan pesisir dan laut. Menurut GESAMP (Group of Expert on the Scientific Aspect on Marine Pollution) (1990) pencemaran laut adalah masuknya atau dimasukkannya zat atau energi oleh manusia baik secara langsung maupun tidak langsung ke lingkungan laut yang menyebabkan efek merugikan kerena merusak sumber daya hayati, membahayakan kesehatan manusia, menghalangi aktifitas di laut termasuk perikanan, menurunkan mutu air laut yang digunakan serta mengurangi kenyamanan di laut. Penambangan timah menghasilkan limbah yang merupakan bahan yang tertinggal setelah pemisahan fraksi bernilai bijih besi. Hal tersebut dianggap bak sampah tak bernilai sehingga salah satunya dapat menyebabkan pencemaran (Agus, 2007).

Aktivitas-aktivitas manusia yang ada pada aliran Sungai Bedukang dapat mengganggu stabilitas ekosistem pada perairan pesisir Bedukang. Perairan laut merupakan tempat yang memiliki peran penting bagi makhluk hidup. Hal tersebut juga dapat menyebabkan penurunan kualitas air yaitu dengan adanya perubahan kondisi fisika, kimia dan biologi (Suparjo, 2009). Adanya limbah yang masuk ke wilayah pesisir tersebut, perlu dilakukan kajian untuk melihat kondisi perairan pesisir Bedukang. Kajian tersebut dilakukan karena perairan ini dimanfaatkan untuk kegiatan perikanan tangkap dan berpotensi sebagai pariwisata. $\mathrm{Hal}$ ini merupakan salah satu langkah awal proses pemantauan dan pencegahan terhadap penurunan kualitas air perairan pesisir Bedukang. Tujuan penelitian adalah untuk menganalisis karakteristik kualitas perairan pesisir Bedukang serta mengkaji tingkat pencemaran di perairan pesisir Bedukang dengan menggunakan Indeks Pencemaran.

\section{METODE PENELITIAN}

Penelitian dilakukan pada bulan Mei 2018 di perairan pesisir Bedukang di Desa Deniang, Kecamatan Riau Silip, Kabupaten Bangka. Peta Lokasi Penelitian dapat dilihat pada Gambar 1.

Pengambilan sampel air laut di lokasi penelitian menggunakan van dorn water sampler ukuran $1 \mathrm{~L}$ dari kedalaman $0-30 \mathrm{~cm}$. Sampel kemudian dimasukkan ke dalam botol polietilen penelitian dan dimasukan kedalam cold box dalam suhu dingin kemudian dianalisis di laboratorium (Amin, 2011). Pada setiap stasiun, dilakukan 3 kali pengulangan.

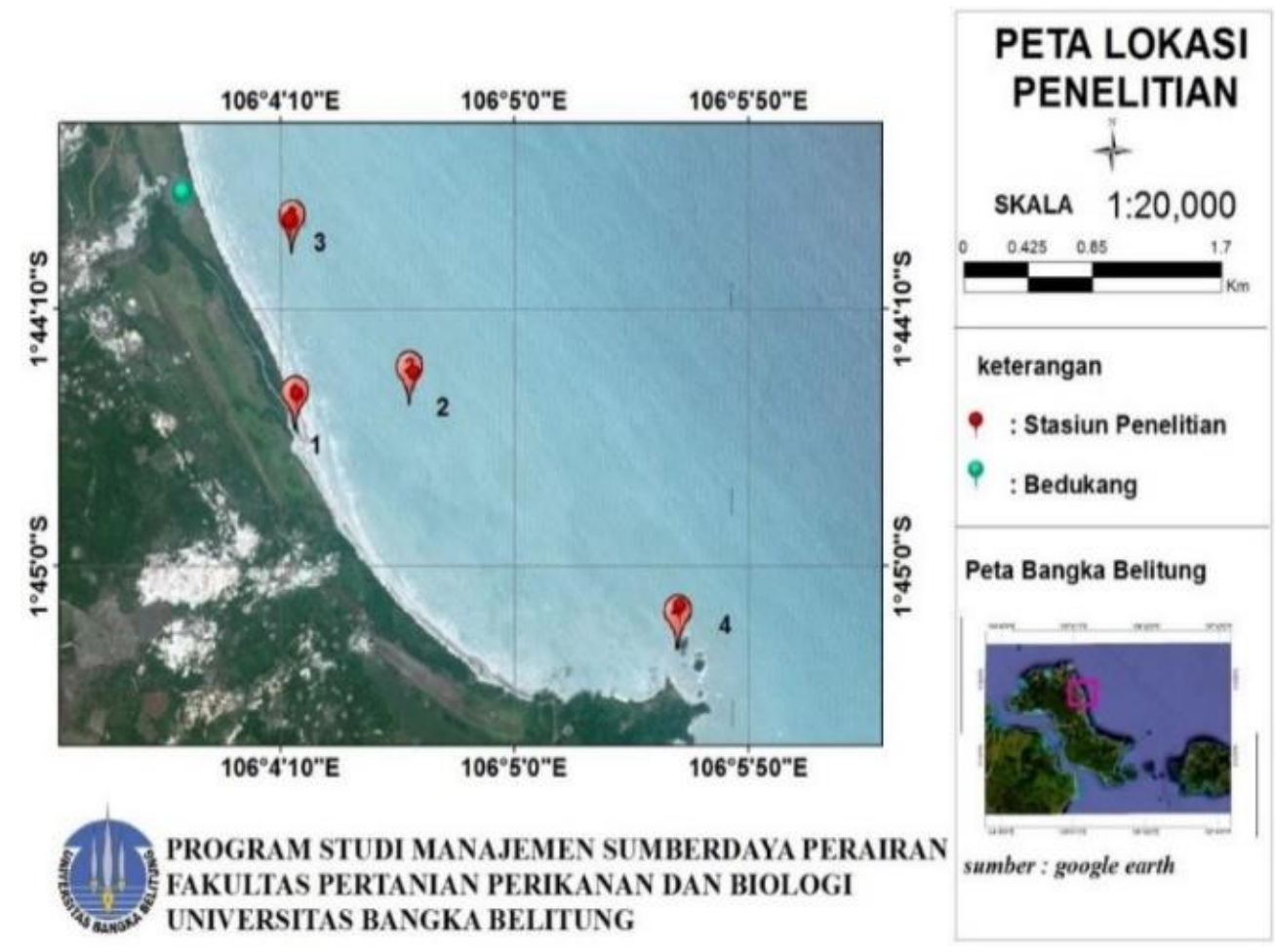

Gambar 1. Lokasi Penelitian 
Pengambilan sampel sedimen menggunakan Van Veen Grab hingga kedalaman mencapai dasar dengan luas bukaan 0,04 $\mathrm{m}^{2}$. Sampel tersebut dimasukkan ke dalam plastik yang telah disediakan untuk dianalisis di laboratorium (Andri, 2012).

Pengujian parameter TSS dan TDS menggunakan metode uji gravimetri (Hadi, 2016) sedangkan pengujian parameter BOD menggunakan metode uji inkubasi dari kandungan oksigen (DO) terlarut yang telah diinkubasi selama 5 hari pada kondisi gelap dan suhu tetap $\left(20^{\circ} \mathrm{C}\right)$ yang sering disebut dengan $\mathrm{DO}_{5}$. Selisih $\mathrm{DO}_{\text {awal }}$ dan $\mathrm{DO}_{5}\left(\mathrm{DO}_{\text {awal }}\right.$ $\mathrm{DO}_{5}$ ) merupakan nilai $\mathrm{BOD}$ yang dinyatakan dalam miligram per liter ( $\mathrm{mg} / \mathrm{L}$ ) (Agustira, 2013). Pengujian parameter Total Coliform menggunakan metode uji Most Probable Number (MPN) dengan menggunakan 5 tabung dengan bantuan bahan Lactose Broth Single Strecht (LBSS), Brilliant Green Lactosa Bile Broth (BGLB) dan larutan $\mathrm{NaCl} 0,85 \%$ (Handayani, 2016). Logam Berat $\mathrm{Pb}$ pada sedimen dilakukan dengan proses sampling berdasarkan metode uji Toxicity Characteristic Leaching Procedure (TCLP) USEPA dan dianalisis dengan alat AAS (Cahaya, 2015) sedangkan pengujian tekstur sedimen menggunakan metode uji analisis kelas tekstur tanah diklasifikasikan menggunakan konsep gradasi USDA (United States Depertement of Agriculture), yaitu menggunakan piramid Soil Classification USDA. Nilai persentase jenis butir sedimen (pasir, liat dan debu) yang telah di dapat dihubungkan untuk tiap masing- masing sampel (Handayani et al., 2017).

\section{Analisis Data}

Keputusan Menteri Lingkungan Hidup Nomor 115 Tahun 2003, Indeks Pencemaran digunakan untuk menentukan tingkat pencemaran relatif terhadap parameter kualitas air yang diizinkan. Hasil dari Indeks Pencemaran ini dapat memberikan masukan kepada pengambil keputusan agar dapat menilai kualitas badan air untuk suatu peruntukan serta dalam memperbaiki kualitas jika terjadi penurunan kualitas akibat kehadiran senyawa pencemar.

Prosedur penggunaan indeks pencemaran dapat dinyatakan dengan nilai $\mathrm{Ci}$ dari konsentrasi hasil analisis parameter kualitas air dan nilai $\mathrm{Li}$ dari konsentrasi parameter kualitas air yang dicantumkan dalam baku mutu air laut. Nilai indeks pencemaran dapat ditentukan dengan cara:
(1) Pilih parameter-parameter yang ada di dalam baku mutu air laut. (2) Hitung harga $\mathrm{Ci} / \mathrm{Li}$ untuk tiap parameter pada setiap lokasi pengambilan sampel. (3) Penggunaan nilai $(\mathrm{Ci} / \mathrm{Li})_{\text {hasil pengukuran }} \mathrm{jika}$ nilai ini lebih kecil dari 1 dan penggunaan $(\mathrm{Ci} / \mathrm{Li})_{\text {baru }}$ jika nilai $(\mathrm{Ci} / \mathrm{Li})_{\text {hasil }}$ pengukuran lebih besar dari 1 . (4) $(\mathrm{Ci} / \mathrm{Li})_{\text {baru }}=1+\mathrm{P} \cdot \log (\mathrm{Ci} / \mathrm{Li})_{\text {hasil pengukuran. }}$ (5) Tentukan nilai rata-rata dan nilai maksimum dari keseluruhan $(\mathrm{Ci} / \mathrm{Li})_{R}$ dan $(\mathrm{Ci} / \mathrm{Li})_{M}$. (6) Tentukan harga Indeks Pencemaran (Tabel 1).

$$
\mathrm{Pij}=\frac{\sqrt{\left(\frac{C i^{2}}{L i j}\right) M+\left(\frac{C i^{2}}{L i j}\right) R}}{2}
$$

Dimana: $: \mathrm{Lij}=$ Konsentrasi parameter kualitas air dalam baku mutu peruntukan air (J) $; \mathrm{Ci}=$ Konsentrasi parameter kualitas air di lapangan; $\mathrm{Pij}=$ Indeks Pencemaran bagi peruntukan $(\mathrm{J}) ;(\mathrm{Ci} / \mathrm{Lij}) \mathrm{R}=$ Nilai, $\mathrm{Ci} / \mathrm{Lij}$ ratarata; $(\mathrm{Ci} / \mathrm{Lij}) \mathrm{M}=$ Nilai, $\mathrm{Ci} / \mathrm{Lij}$ maksimum

Tabel 1. Kriteria Indeks Pencemaran

Indeks Mutu Perairan

Pencemaran

$\begin{array}{cc}0 \leq \mathrm{Pij} \leq 1 & \text { Baik } \\ 1<\mathrm{Pij} \leq 5 & \text { Cemar ringan } \\ 5<\mathrm{Pij} \leq 10 & \text { Cemar sedang } \\ \mathrm{Pij}>10 & \text { Cemar berat }\end{array}$

HASIL DAN PEMBAHASAN

\section{Karakteristik Parameter Fisika, Kimia dan Biologi Perairan Pesisir Bedukang}

Hasil pengukuran parameter kualitas air tahun 2018 pada parameter suhu yang diperoleh berkisar antara $29^{\circ} \mathrm{C}-21^{\circ} \mathrm{C}$. Ratarata tertinggi suhu berada pada stasiun 1 , stasiun 3 dan stasiun 4 dengan nilai $30,33^{\circ} \mathrm{C}$ dan rata-rata terendah pada stasiun 2 dengan nilai $29,67^{\circ} \mathrm{C}$. Parameter TSS memiliki kisaran 18,4 mg/L - $204 \mathrm{mg} / \mathrm{L}$. Rata-rata tertinggi parameter TSS berada pada stasiun 1 dengan nilai $174 \mathrm{mg} / \mathrm{L}$ dan rata-rata terendah pada stasiun 2 dengan nilai $19 \mathrm{mg} / \mathrm{L}$. Parameter TDS memiliki kisaran 15,45 mg/L - 170,8 mg/L. Rata-rata tertinggi parameter TDS berada pada stasiun 1 dengan nilai 129,6 mg/L dan rata-rata terendah berada pada stasiun 2 dengan nilai $18,62 \mathrm{mg} / \mathrm{L}$. Hasil Pengukuran kualitas air lainnya dapat dilihat pada Tabel 2 .

Suhu perairan maksimal ditemukan pada stasiun 1 , stasiun 3 dan stasiun 4 dengan nilai $30,33^{\circ} \mathrm{C}$ sedangkan suhu perairan minimum ditemukan pada stasiun 2 
dengan nilai $29^{\circ} \mathrm{C}$ yang dimana kondisi tersebut tergolong suhu alami normal. Hal ini sejalan dengan pendapat Kurniawan et al. (2014) bahwa suhu permukaan perairan wilayah laut berkisar antara $28^{\circ} \mathrm{C}-32^{\circ} \mathrm{C}$ yang termasuk kondisi yang tergolong suhu normal. Menurut Ilahude dan Liasaputra (1980) bahwa suhu di perairan laut tropis berkisar antara 25,6 - 32,3 ${ }^{\circ} \mathrm{C}$, sedangkan menurut Suwari (2010) antara 20 - $30^{\circ} \mathrm{C}$. Effendie (2003) menambahkan jika suhu perairan mencapai $35^{\circ} \mathrm{C}-40^{\circ} \mathrm{C}$ merupakan suhu kritis bagi kehidupan organisme yang dapat menyebabkan kematian.

Hasil pengukuran terhadap padatan tersuspensi (TSS) perairan menunjukan bahwa lokasi pengamatan yang berada pada muara sungai memiliki nilai TSS tinggi dibandingkan lokasi pengamatan yang berada di lepas pantai. Nilai TSS pada stasiun 1 yaitu $174 \mathrm{mg} / \mathrm{L}$ dan nilai TSS terendah pada stasiun 2, stasiun 3 dan stasiun 4 yaitu rentang nilai $19 \mathrm{mg} / \mathrm{L}$. Kandungan zat padat tersuspensi diduga belum menimbulkan bahaya dan dampak negatif pada stasiun 2, stasiun 3 dan stasiun 4. Namun, pada stasiun 1 merupakan nilai TSS tertinggi dimana US-
EPA (1973) menyebutkan bahwa pengaruh padatan tersuspensi sangat beragam, tergantung pada sifat kimia alamiah bahan tersuspensi tersebut, khususnya bahan toksik. Kurniawan et al. (2014) menambahkan tingginya padatan tersuspensi diakibatkan kegiatan penambangan timah yang dilihat dari metode penambangan melakukan penggerukan. Dasar perairan yang mengalami pengerukkan terdapat sisa dari pecahan batuan atau pasir yang berhamburan di dasar perairan. padatan tersuspensi (TSS) diperairan yang terdapat kegiatan penambangan timah sangat tinggi. Pernyataan tersebut sesuai dengan kondisi di lapangan karena stasiun 1 merupakan muara sungai yang mana limbah yang dihasilkan dari proses tailing timah dibuang ke badan perairan Sungai Bedukang sehingga nilai padatan tersuspensinya tinggi.

Nilai padatan terlarut (TDS) tertinggi yaitu $129,6 \mathrm{mg} / \mathrm{L}$ pada stasiun 1 dan nilai TDS terendah pada stasiun 2 yaitu 18,62 mg/L. Berdasarkan Keputusan Menteri Lingkungan Hidup No.51 Tahun 2004 tentang Baku Mutu Air Laut yaitu nilai TDS yang memenuhi baku mutu perairan yaitu memiliki

Tabel 2. Hasil Pengukuran Parameter Kualitas Air

\begin{tabular}{|c|c|c|c|c|c|c|c|c|}
\hline \multirow{4}{*}{ No } & \multirow{2}{*}{ Parameter } & \multicolumn{4}{|c|}{ FISIKA } & \multicolumn{2}{|c|}{ KIMIA } & \multirow{2}{*}{$\begin{array}{c}\text { BIOLOGI } \\
\text { Total Coliform }\end{array}$} \\
\hline & & Suhu & TSS & TDS & Salinitas & BOD & $\mathrm{pH}$ & \\
\hline & Baku mutu* & $28-30$ & 80 & - & $30-31$ & 20 & $7-8,0$ & 1000 \\
\hline & Stasiun/Satuan & ${ }^{\circ} \mathrm{C}$ & $\mathrm{mg} / \mathrm{L}$ & $\mathrm{mg} / \mathrm{L}$ & $\mathrm{mg} / \mathrm{L}$ & $\mathrm{mg} / \mathrm{L}$ & - & $\mathrm{MPN} / 100 \mathrm{~mL}$ \\
\hline \multirow{5}{*}{1} & sub 1 & 30 & 164 & 170,8 & 30 & 41 & 8 & 132 \\
\hline & sub 2 & 31 & 204 & 108 & 31 & 49,5 & 7 & 13 \\
\hline & sub 3 & 30 & 154 & 110 & 31 & 38,8 & 8 & 17 \\
\hline & Rata-rata & 30,33 & 174 & 129,6 & 30,67 & 43,1 & 7,67 & 54 \\
\hline & Std Deviasi & 0,58 & 26,46 & 35,69 & 0,58 & 5,65 & 0,58 & 67,58 \\
\hline \multirow{5}{*}{2} & sub 1 & 30 & 19,6 & 15,45 & 33 & 4,7 & 8 & 12 \\
\hline & sub 2 & 29 & 19 & 24,1 & 33 & 4,7 & 8 & 104 \\
\hline & sub 3 & 30 & 18,4 & 16,3 & 32 & 4,4 & 7 & 6 \\
\hline & Rata-rata & 29,67 & 19 & 18,62 & 33,67 & 4,6 & 7,67 & 40,67 \\
\hline & Std Deviasi & 0,58 & 0,60 & 4,77 & 0,58 & 0,17 & 0,58 & 54,93 \\
\hline \multirow{5}{*}{3} & sub 1 & 30 & 19,8 & 23,9 & 33 & 4,8 & 7 & 227 \\
\hline & sub 2 & 31 & 20,6 & 24 & 32 & 5 & 8 & 39 \\
\hline & sub 3 & 30 & 19,4 & 24,1 & 33 & 4,7 & 8 & 15 \\
\hline & Rata-rata & 30,33 & 19,93 & 24,00 & 33,67 & 4,83 & 7,67 & 93,67 \\
\hline & Std Deviasi & 0,58 & 0,61 & 0,10 & 0,58 & 0,15 & 0,58 & 116,09 \\
\hline \multirow{5}{*}{4} & sub 1 & 30 & 19 & 24,2 & 30 & 4 & 8 & 13 \\
\hline & sub 2 & 31 & 18,8 & 24,2 & 31 & 4,5 & 8 & 14 \\
\hline & sub 3 & 30 & 19,2 & 23,8 & 31 & 4,7 & 7 & 12 \\
\hline & Rata-rata & 30,33 & 19,00 & 24,07 & 30,67 & 4,40 & 7,67 & 13,00 \\
\hline & Std Deviasi & 0,58 & 0,20 & 0,23 & 0,58 & 0,36 & 0,58 & 1,00 \\
\hline
\end{tabular}

Keterangan : * Kepmen LH No. 51 tahun 2004 tentang Baku Mutu Air Laut (Biota Laut) 
rentang nilai $20-80 \mathrm{mg} / \mathrm{L}$. Nilai TDS pada stasiun 2, stasiun 3 dan stasiun 4 masih memenuhi baku mutu perairan tetapi tidak memenuhi pada stasiun 1 . Hal tersebut karena pada stasiun 1 merupakan salah satu sumber masuknya limbah tailing timah sehingga nilai padatan terlarutnya tinggi. Said et al. (2009) menambahkan bahwa semakin banyak bahan (mineral logam maupun non logam) dalam air maka hasil pengukuran padatan terlarut akan semakin tinggi.

Pengukuran salinitas di lapangan selama 3 kali pengulangan pada masingmasing stasiun memiliki nilai rata-rata yang berbeda yaitu pada stasiun 1 dan stasiun 4 memiliki rata-rata nilai $33,67 \mathrm{mg} / \mathrm{L}$. Ukuran salinitas tersebut berada dibawah batas normal perairan laut sesuai dengan KepMen.LH No. 51 tahun 2004 tentang Baku Mutu Air Laut dengan peruntukkan biota laut yang rentang nilainya untuk mangrove 34 $\mathrm{mg} / \mathrm{L}$ dan untuk terumbu karang $33 \mathrm{mg} / \mathrm{L}$ $34 \mathrm{mg} / \mathrm{L}$. Rendahnya nilai salinitas pada perairan pesisir Bedukang diduga karena pada saat pengambilan data, kondisi perairan dalam keadaan hujan dan gelombang yang cukup tinggi. Kurniawan et al. (2014) menyatakan bahwa banyak faktor yang mempengaruhi salinitas salah satunya adalah penguapan. Makin besar tingkat penguapan air laut di suatu wilayah, maka salinitasnya tinggi dan sebaliknya pada daerah yang rendah tingkat penguapan air lautnya, maka daerah tersebut rendah kadar garamnya. Hujan merupakan salah satu faktor yang mempengaruhi salinitas jika curah hujan tinggi maka salinitas air laut rendah dan sebaliknya jika curah hujan ke rendah maka salinitas akan tinggi. Nugraha (2007) menambahkan curah hujan yang semakin besar/banyak di suatu wilayah laut maka akan mempengaruhi salinitas air laut menjadi rendah dan sebaliknya makin sedikit/kecil curah hujan yang turun salinitas akan tinggi.

BOD merupakan gambaran secara tidak langsung tentang konsentrasi bahan organik dalam air, oleh karena itu kandungan BOD biasa digunakan sebagai indikator terjadinya pencemaran akibat berlimpahnya bahan organik di perairan, BOD berfungsi untuk memecah bahan-bahan buangan didalam air (Valentina, 2013). Nilai BOD pada stasiun 1 merupakan nilai tertinggi sebesar $43,1 \mathrm{mg} / \mathrm{L}$ hal tersebut diduga karena pada stasiun tersebut merupakan lokasi muara dimana pertemuan antara air laut dan air tawar, sehingga mendapat banyak masukan bahan organik dari aliran sungai menuju muara, maka semakin tinggi kandungan bahan organik yang masuk ke perairan, semakin banyak oksigen yang dibutuhkan mikroorganisme. Studi pemodelan kualitas air dengan parameter BOD dan DO pada sungai ciliwung (Budiman, 2010) menunjukan hasil penelitian kadar BOD memiliki nilai 100-200 $\mathrm{mg} / \mathrm{L}$. BOD yang cenderung naik menunjukkan jumlah pemakaian oksigen yang dibutuhkan oleh mikroorganisme untuk menguraikan senyawa organik semakin bertambah sebanding dengan bertambahnya waktu. BOD merupakan parameter pencemar kimia untuk limbah organik, maka semakin tinggi nilai konsentrasi BOD di suatu perairan maka semakin tinggi kandungan limbah organik di perairan tersebut. Namun, Nilai BOD berdasarkan baku mutu air laut KepMen.LH No. 51 tahun 2004 tentang Baku Mutu Air Laut tidak memenuhi pada stasiun 1 karena tidak sesuai peruntukkan biota laut.

Nilai pada stasiun 2, stasiun 3 dan stasiun 4 memiliki nilai BOD $4,4 \mathrm{mg} / \mathrm{L}$ sampai $4,83 \mathrm{mg} / \mathrm{L}$. Hal tersebut serupa dengan studi tentang kondisi kualitas perairan di Pelabuhan Sunda Kepala, DKI Jakarta (Siregar, 2006) yang menunjukkan hasil BOD pada bulan Oktober 2005 sebesar 3,41 mg/L hingga $5,28 \mathrm{mg} / \mathrm{L}$. Hasil pengukuran tersebut menunjukan nilai BOD yang relative rendah. Rendahnya nilai BOD pengamatan diperkirakan sebagai implikasi dan relative baiknya proses pengurairan bahan organik oleh aktivitas mikroba. Hasil pengukuran BOD pada stasiun 2, stasiun 3 dan stasiun 4 masih berada diatas nilai minimal BOD yaitu untuk peruntukkan biota laut sebesar $10 \mathrm{mg} / \mathrm{L}$ berdasarkan baku mutu air laut Kep-Men.LH No. 51 tahun 2004 tentang Baku Mutu Air Laut tidak memenuhi pada stasiun 1 karena tidak sesuai peruntukkan biota laut.

Hasil pengamatan parameter $\mathrm{pH}$ perairan pesisir Bedukang memiliki rerata nilai 7,67 . Nilai kisaran rata-rata $\mathrm{pH}$ pada antar stasiun hampir sama, tidak terlihat adanya perbedaan yang nyata. Hal tersebut sejalan dengan pernyataan Siregar (2006) yang menyatakan bahwa nilai $\mathrm{pH}$ di lingkungan perairan laut relative stabil dengan kisaran yang sempit. Penelitian Rinawati (2016) menambahkan perairan laut maupun pesisir memiliki pH relatif lebih stabil dan berada dalam kisaran yang sempit, karena dipengaruhi oleh kapasitas penyangga (buffer) yaitu adanya garam-garam karbonat dan bikarbonat yang dikandungnya. Berdasarkan hasil pengukuran $\mathrm{pH}$ sampel pada perairan Teluk Lampung menunjukkan nilai $\mathrm{pH}$ perairan basa dan cenderung stabil 
pada rentang nilai 6,53-8,23. Berdasarkan nilai baku mutu air laut Kep-Men.LH No. 51 tahun 2004 tentang Baku Mutu Air Laut sesuai peruntukkan biota laut tidak memenuhi baku mutu karena nilainya kurang dari kriteria yang ditentukan yaitu sebesar 78,5. Kurniawan et al. (2014) menyatakan bahwa terdapat 2 fungsi dari $\mathrm{pH}$ yaitu sebagai faktor pembatas, setiap organisme mempunyai toleransi yang berbeda terhadap $\mathrm{pH}$ maksimal, minimal serta optimal dan sebagai indeks keadaan lingkungan. Nilai $\mathrm{pH}$ air yang normal yaitu antara 6-8, sedangkan $\mathrm{pH}$ air tercemar beragam tergantung dari jenis buangannya.

Kandungan total coliform pada perairan pesisir Bedukang memiliki nilai yang bervariasi. Nilai tertinggi total coliform beraada pada stasiun 3 dengan nilai 93,67 MPN/100 ml. Nilai terendah berada pada stasiun 4 dengan nilai 13 MPN/100 ml. Pada stasiun 1 dan stasiun 2 memiliki nilai masingmasing 54 MPN/100 ml dan 40,67 MPN/100 ml. Namun, kandungan total coliform pada keseluruhan stasiun masih dibawah baku mutu air laut KepMenLH No. 51 tahun 2004 tentang Baku Mutu Air Laut senilai 1000 MPN/100 ml.

Tingginya kandungan coliform pada stasiun 3 diduga karena pada stasiun tersebut terdapat perternakan babi, hal tersebut diperkuat pada saat pengamatan dilapangan terdapat babi yang berkeliaran disekitar pesisir pantai. Selain adanya perternakkan babi, kotoran hewan seperti anjing liar yang berkeliaran disekitar perairan pesisir Bedukang memberikan kontaminasi dengan membuang feses yang mengandung bakteri Escherichia coli. Hal tersebut sejalan dengan pernyataan Hazar et al. (2012), bakteri Escherichia coli dapat ditemukan pada feses ayam, kambing, domba, babi dan anjing Namun, pernyataan tersebut berbanding terbalik pada kondisi stasiun 4 dimana pada stasiun memiliki kandungan coliform terendah. Hal itu diduga karena tidak adanya perternakkan babi disekitar perairan dan tidak adanya hewan anjing yang berkeliaran karena pada stasiun 4 merupakan daerah tempat berlabuhnya kapal-kapal nelayan.

Analisis tekstur sedimen dilakukan untuk mengetahui jenis tekstur pada perairan pesisir Bedukang. Stasiun 1 memiliki presentase pasir 26,4\%, debu $24,8 \%$ dan liat $48,8 \%$. Stasiun 2 memiliki presentase pasir $55,9 \%$, debu $27,4 \%$ dan liat $16,7 \%$. Stasiun 3 memiliki presentase pasir 10,1\%, debu $56,5 \%$ dan liat $33,3 \%$. Stasiun 4 memiliki presentase berat pasir $40 \%$, debu $36,7 \%$ dan liat 23,3\%. Masing-masing jenis tekstur substratnya dapat dilihat pada Tabel 3 .

Tipe substrat dasar perairan pesisir ditentukan oleh arus dan gelombang. Kecepatan arus dan gelombang menentukan jenis atau ukuran butiran partikel yang diendapkan. Menurut Taqwa (2014) substrat daerah pesisir terdiri dari bermacam-macam tipe antara lain lumpur, lumpur berpasir, pasir dan berbatu. Kapasitas penyebaran logam berat sangat berhubungan dengan ukuran partikel dan luas permukaan penyerapan, sehingga kandungan logam berat dalam sedimen biasanya dipengaruhi oleh ukuran partikel dalam sedimen.

Tekstur sedimen di perairan pesisir Bedukang terdiri oleh jenis liat dan lempung. Berdasarkan analisis tekstur segitiga tekstur, tekstur sedimen dilokasi penelitian dapat dikategorikan menjadi 4 yaitu liat, lempung berpasir, lempung berlumpur dan lempung. Pada stasiun 1 yaitu di muara sungai di dominasi oleh substrat liat sebesar 48,8\%. $24 \%$ debu dan $26,4 \%$ pasir sehingga dikategorikan jenis substrat liat. Kondisi tersebut sesuai dengan pendapat Said et al. (2009) bahwa ekosistem estuari didominasi oleh substrat lumpur (tekstur liat dan debu). Pada perairan lepas pantai yaitu pada stasiun 2 , stasiun 3 dan stasiun 4 didominansi oleh substrat pasir dan debu. Hal tersebut sesuai dengan penelitian Lindawaty et al. (2016) perairan litoral sebagian di daerah pasang surut dan air tawar umumnya terdapat didasar perairan yang berlumpur atau berpasir.

Tabel 3. Tekstur Sedimen pada Setiap Stasiun

\begin{tabular}{ccccc}
\hline \multirow{2}{*}{ Stasiun } & \multicolumn{3}{c}{ Persentase Berat (\%) } & \multirow{2}{*}{ Substrat } \\
\cline { 2 - 4 } & Pasir & Debu & Liat & \\
\hline Stasiun 1 & 26,4 & 24,8 & 48,8 & Liat \\
Stasiun 2 & 55,9 & 27,4 & 16,7 & Lempung Berpasir \\
Stasiun 3 & 10,1 & 56,5 & 33,3 & Lempung Berlumpur \\
Stasiun 4 & 40 & 36,7 & 23,3 & Lempung \\
\hline
\end{tabular}


Tabel 4. Kandungan Logam $\mathrm{Pb}(\mathrm{mg} / \mathrm{kg}$ ) pada Setiap Stasiun

\begin{tabular}{cc}
\hline Stasiun & Kandungan Logam Pb \\
\hline 1 & 0,09 \\
2 & 0,11 \\
3 & 0,5 \\
4 & 0,5 \\
\hline
\end{tabular}

Analisis logam $\mathrm{Pb}$ pada sedimen dilakukan untuk mengetahui jika konsentrasi logam berat telah melebihi baku mutu dalam perairan sehingga dapat terakumulasi pada sedimen di perairan pesisir Bedukang. Kisaran logam $\mathrm{Pb}$ pada sedimen berkisar antara 0,09-0,11 mg/kg. Pada stasiun 3 dan 4 memiliki nilai kandungan logam $\mathrm{Pb}$ yang paling rendah yaitu $<0,09 \mathrm{mg} / \mathrm{kg}$ dan pada stasiun 1 dan stasiun 2 memiliki nilai 0,09 $\mathrm{mg} / \mathrm{kg}$ dan $0,11 \mathrm{mg} / \mathrm{kg}$. Hasil Pengukuran logam $\mathrm{Pb}$ pada masing-masing stasiun dapat dilihat pada Tabel 4.

Nilai kandungan logam berat $\mathrm{Pb}$ dalam sedimen di perairan pesisir Bedukang memiliki nilai yang tergolong rendah. Kandungan logam $\mathrm{Pb}$ pada sedimen di perairan pesisir terendah berada stasiun 3 dan stasiun 4 yaitu $<0,09 \mathrm{mg} / \mathrm{kg}$. Nilai logam tertinggi terdapat pada stasiun 2 yaitu 0,11 $\mathrm{mg} / \mathrm{kg}$. Hasil pengamatan tersebut relatif rendah, karena hasil studi di Maluku Tenggara oleh Edward (2011) menyebutkan bahwa kandungan logam $\mathrm{Pb}$ dalam sedimen relatif tidak tercemar dan masih alami, berkisar <0,004-0,274 mg/kg. Nilai ambang batas $\mathrm{Pb}$ dalam sedimen untuk perlindungan biota adalah $35 \mathrm{mg} / \mathrm{kg}$ (Canadian Council of Ministers for the Environment, 2002). KMNLH (2010) menetepkan nilai ambang batas kandungan logam $\mathrm{Pb}$ dalam sedimen untuk kehidupan biota adalah $36,8 \mathrm{mg} / \mathrm{kg}$. Kadar rerata $\mathrm{Pb}$ alami yang terdapat di lapisan permukaan bumi adalah $12,5 \mathrm{mg} / \mathrm{kg}$ (Mohiuddin et al., 2010). Kandungan logam $\mathrm{Pb}$ pada perairan pesisir saat ini masih aman untuk kehidupan biota laut. Meskipun logam berat $\mathrm{Pb}$ yang terdapat dalam sedimen masih berada di bawah baku mutu perairan, perlu diwaspadai pula keberadaannya pada biota laut seperti ikan-ikan demersal (Ahmad, 2013).

Mukhtasor (2007) menyatakan bahwa material pengerukan yang dibuang di perairan laut memiliki densitas yang rendah, akan menyebar di badan air laut karena dipengaruhi oleh gerakan air, walaupun pada akhirnya turun karena berat jenisnya sedikit lebih besar daripada air. Perairan pesisir Bedukang merupakan salah satu perairan laut terbuka dimana perairan tersebut bergerak dinamis yang diakibatkan oleh angin dan gerakan pasang surut. Pada lapisan termoklin, densitas material menjadi relatif rendah dibanding densitas air laut, sehingga material tidak mengendap di dasar.

\section{Nilai Indeks Pencemaran}

Perhitungan parameter kualitas air pada 4 stasiun dengan menggunakan Indeks Pencemaran memiliki kisaran nilai 0,980 2,819. Nilai Indeks Pencemaran tertinggi diperoleh nilai indeks pencemaran pada stasiun 1 dengan nilai 2,819. Pencemaran terendah diperoleh pada stasiun 2 dengan nilai 0,980 (Tabel 5).

Indeks Pencemaran merupakan salah satu metode yang digunakan untuk mengetahui status mutu perairan. Indeks Pencemaran tertinggi pada perairan pesisir Bedukang berada pada stasiun 1 dengan nilai 2,819 yang termasuk ke dalam mutu perairan tercemar ringan. Stasiun 3 dan stasiun 4 termasuk kategori tercemar ringan dengan nilai indeks pencemaran masingmasing 1,029 dan 1,022. Nilai indeks pencemaran terendah berada pada stasiun 2 dengan nilai 0,980 termasuk kategori mutu perairan baik.

Pada stasiun 1 indeks pencemarannya lebih tinggi dibandingkan dengan stasiun lain. Hal ini disebabkan karena pada stasiun 1 merupakan muara sungai yang telah menerima buangan limbah dari sungai menuju laut. Hal ini sejalan dengan penelitian Suhartono (2009), perairan yang termasuk tercemar berat lebih cenderung berada dari sumber limbah yang dihasilkan Namun, hal tersebut berbanding terbalik dengan hasil indeks pencemaran pada stasiun 2, karena pada stasiun tersebut merupakan lokasi perairan laut yang memiliki nilai indeks pencemaran terendah. Hal tersebut diduga karena pada saat pengambilan data dipengaruhi oleh arus dan gelombang yang cukup tinggi. Pernyataan tersebut sesuai dengan Montagna et al. (2013) menyatakan terdapat tiga komponen yang menyebabkan nilai indeks pencemaran menjadi rendah, yaitu iklim, geologi dan pasang surut. Iklim terkait dengan variasi penguapan dan limpasan air tawar, geologi terkait dengan variasi ketinggian dan pola drainase serta pasang surut terkait dengan tingkat percampuran dan elevasi percampuran air. Berkaitan dengan menurunnya cemaran di 
Tabel 5. Nilai Indeks Pencemaran

\begin{tabular}{|c|c|c|c|c|c|}
\hline \multirow[b]{2}{*}{ Stasiun } & \multirow{2}{*}{$\begin{array}{c}\text { Nilai } \\
\text { Pij }\end{array}$} & \multicolumn{4}{|c|}{ Kriteria Pencemaran } \\
\hline & & $\begin{array}{c}0 \leq \text { Pij } \leq 1 \\
\text { Baik }\end{array}$ & $\begin{array}{c}1<\mathrm{Pij} \leq 5 \\
\text { Tercemar Ringan }\end{array}$ & $\begin{array}{c}5<\mathrm{Pij} \leq 10 \\
\text { Tercemar Sedang }\end{array}$ & $\begin{array}{c}\mathrm{Pij}>10 \\
\text { Tercemar } \\
\text { Berat }\end{array}$ \\
\hline 1 & 2,819 & & $\sqrt{ }$ & & \\
\hline 2 & 0,980 & $\sqrt{ }$ & & & \\
\hline 3 & 1,029 & & $\sqrt{ }$ & & \\
\hline 4 & 1,022 & & $\sqrt{ }$ & & \\
\hline
\end{tabular}

muara, hal ini dapat terjadi karena pada saat pengambilan contoh air kondisi sedang pasang. Indeks Pencemaran, tingkat pencemaran dinyatakan tercemar berat apabila rasio parameter terukur sebagian besar nilainya lebih dari 63 kali baku mutu peruntukannya (Riza et al., 2015).

Pada stasiun 3 dan stasiun 4 yang nilainya termasuk kedalam kategori mutu perairan tercemar ringan. Hal ini menunjukkan bahwa pada stasiun 3 terdapat aktivitas pertenakan babi dan anjing yang berkeliaran sedangkan pada stasiun 4 terdapat tempat berlabuhnya kapal-kapal, tidak memberikan efek berlebih terhadap badan perairan pesisir Bedukang. Hal tersebut diduga karena telah terjadinya pengenceran terhadap buangan limbah pada air laut. Menurut Effendi (2003), air limbah yang mengalami porifikasi alami salah satunya dengan pengenceran yang mana limbah tersebut dibuang ke suatu badan perairan agar mengalami pengenceran agar mengalami purifikasi alami. Badan perairan tersebut harus memiliki kandungan oksigen yang cukup, dengan kata lain air harus mengalir. Pernyataan tersebut serupa dengan Rochyatun et al. (2010) yang menyatakan proses pengenceran dibantu oleh pasang surut air laut.

\section{KESIMPULAN}

Karakteristik parameter fisika dan parameter biologi masih sesuai dengan Baku Mutu Air Laut Kep-MenLH No. 51 Tahun 2004. Namun, pada parameter kimia yang tidak sesuai dengan Baku Mutu Air Laut KepMenLH No. 51 Tahun 2004 yaitu parameter BOD pada stasiun 1. Nilai Indeks Pencemaran pada stasiun 1 , stasiun 3 dan stasiun 4 termasuk kedalam tercemar ringan dengan nilai masing-masing nilai 2,819, 1,025 dan 1,022. Sedangkan, stasiun 2 nilai indeks pencemarannya sebesar 0,919 termasuk kategori mutu perairan baik.

\section{REFERENSI}

Agus, A. 2007. Kandungan Penambangan Timah yang Dapat Dimanfaatkan Sebagai Tenaga Nuklir. BATAN. Jakarta

Agustira, R., Lubis, K.S., Jamilah. 2013. Kajian Karakteristik Kimia Air, Fisika Air dan Debit Sungai pada Kawasan Das Padang Akibat Pembuangan Limbah Tapioka. Jurnal Online Agroekoteknologi. 1(3):615-625.

Ahmad, F. 2013. Distribusi dan Prediksi Tingkat Pencemaran Logam Berat $(\mathrm{Pb}$, $\mathrm{Cd}, \mathrm{Cu}, \mathrm{Zn}$, dan Ni) Dalam Sedimen di Perairan Pulau Bangka Menggunakan Indeks Beban Pencemaran dan Indeks Geoakumulasi. Jurnal IImu dan Teknologi Kelautan Tropis. 5(1):170181.

Amin, B. 2011. Distribusi Spasial Logam Pb dan $\mathrm{Cu}$ pada Sedimen dan Air Laut Permukaan di Perairan Tanjung Buton Kabupaten Siak Provinsi Riau. Jurnal Teknobiologi. 2(1):1-8.

Andri, Y.S., Endrawati, H., Zainuri, M. 2012. Struktur Komunitas Makrozoobentos di Perairan Morosari, Kecamatan Sayung, Kabupaten Demak. Journal of Marine Research. 1(2):235-242.

Budiman, A. 2010. Pemodelan Kualitas Air dengan Parameter BOD dan DO pada Sungai Ciliwung. Jurnal Teknik Lingkungan. 5(3)97-106.

Cahaya, I. 2015. Studi Pelepasan Kadmium (Cd) dan Nikel (Ni) pada Sedimen secara Metode Toxicity Characteristic Leaching Procedure (TCLP) dan Uji Sifat Bioakumulasinya melalui Simulasi pada Cyprinus Carpio. Jurnal Sains Dasar. 4(1):55-64.

Canadian Council of Ministers for the Environment (CCME). 2002. Canadian sediment quality guidelines for the protection of aquatic life summary table. CCME. Winnipeg, MB. 7p. 
Lindawaty, L., Dewiyanti, I. dan Karina, S. 2016. Distribusi dan Kepadatan Kerang Darah (Anadara sp.) Berdasarkan Tekstur Substrat di Perairan Ulee Lheue Banda Aceh. Jurnal IImiah Mahasiswa Kelautan dan Perikanan Unsyiah. 1(1):114-123.

Edward. 2011. Kualitas air laut dan sumberdaya perikanan di perairan Elat, Kepulauan Kai Besar Maluku Tenggara. Laporan penelitian LIPIRISTEK. Tidak diterbitkan. $119 \mathrm{hlm}$.

Effendi, H. 2003. Telaah Kualitas Air : Bagi Pengelolaan Sumber Daya Alam dan Lingkungan Perairan. Penerbit Kanisius. Yogyakarta.

GESAMP. 1990. The State of the Marine Environment. Blackwell Scientific Publications, Oxford.

Handayani, N.I. 2016. Komparasi Analisis Total Coliform dan Coli Tinja dengan Menggunakan Metode Most Probable Number (MPN) 5tabung dan enzim substrat. Jurnal Riset Teknologi Pencegahan Pencemaran Industri. 2(6): 105-112.

Handayani, S., Jumarang, M.I., Apriansyah. 2017. Identifikasi Jenis Material Sedimen Dasar Kelokan Sungai di Desa Sungai Duri Kecamatan Bengkayang Kabupaten Bengkayang. Prisma Fisika. 5(3): $145-150$.

Hazar, M., Salim, M., Mardiah, E. 2012. Keberadaan Escherichia coli Resistan Antibiotik pada Ikan Baling (Pristolepis fasciata) di Sungai Batang Arau. Jurnal Penelitian Fmipa Unand.

Keputusan Menteri Lingkungan Hidup (KMNLH) Nomor: 51/MENLH/2004 Tahun 2004, tentang penetapan baku mutu air laut dalam himpunan peraturan di bidang lingkungan hidup. Jakarta.

Kurniawan, Supriharyono, Sasongko DP. 2014. Pengaruh Kegiatan Penambangan Timah Terhadap Kualitas Air Laut di Wilayah Pesisir Kabupaten Bangka Provinsi Kepulauan Bangka Belitung. Jurnal Sumberdaya Perairan. 8(1): 1322.

Mohiuddin, M.K., H.M. Zakir, K. Otomo, S. Sharmin, N. Shikazono. 2010. Geochemical distribution of trace metal pollutants in water and sediments of downstream of an urban river. Int. J. Environ. Sci. Tech., 7(1):17-28.

Montagna P, Palmer T, Beseres P. 2013. Hydrobiological changes and estuarine dynamics. Env. Science. doi: 10.1007/978-1-4614-5833-3_2.

Springer Publishing.

Mukhtasor. 2007. Pencemaran Pesisir dan Laut. PT Pradnya Paramita. Jakarta.

Nugraha, W.D. dan Cahyorini, L. 2007. Identifikasi Daya Tampung Beban Cemaran BOD Sungai dengan Model Qual2e (Studi Kasus Sungai Gung, Tegal-Jawa Tengah). Jurnal Presipitasi: Media Komunikasi dan Pengembangan Teknik Lingkungan. 3(2): 18.

Rinawati, D. Hidayat, R. Suprianto, dan P.S. Dewi. 2016. Penentuan Kandungan Zat Padat (Total Dissolve Solid dan Total Suspended Solid) di Perairan Teluk Lampung. Jurnal Analit:Analytical and Environtment Chemistry. 1(1):36-46

Riza, F., Bambang, A.N. and Kismartini, K., 2015. Tingkat Pencemaran Lingkungan Perairan Ditinjau Dari Aspek Fisika, Kimia Dan Logam Di Pantai Kartini Jepara. Indonesian Journal of Conservation, 4(1):52-60

Rochyatun, E., Kaisupy M. T., dan Rozak, A. 2006. Distribusi Logam Berat dalam Air dan Sedimen Diperairan Muara Sungai Cisadane. Makara Sains, 10(1):35-40.

Said, Irwan., Jalaluddin, M.N., Upe, A. dan Wahab, A.W. 2009. Penetapan Konsentrasi Logam Berat Krom dan Timbal dalam Sedimen Estuaria Sungai Matangpondo Palu. Jurnal Chemica. $10(2): 40-47$

Siregar, M.R.Y. 2006. Kondisi Kualitas Perairan di Pelabuhan Sunda Kelapa, DKI Jakarta. [Tesis]. Bogor (ID): Institut Pertanian Bogor.

Suhartono, E. 2009. Identifikasi Kualitas Perairan Pantai Akibat Limbah Domestik pada Monsun Timur dengan Metode Indeks Pencemaran. Wahana Teknik Sipil. 14(1):51-62.

Suparjo, M.N. 2009. Kondisi Pencemaran Perairan Sungai Babon Semarang. Jurnal Saintek Perikanan. 4(2):38-45.

Suprapto, S.J. 2008. Tinjauan Reklamasi Lahan Bekas Tambang dan Aspek Konservasi Bahan Galian. Kelompok Program Penelitian Konservasi - Pusat Sumber Daya Geologi. Jakarta.

Suwari, R.E, Pramudya B, Djuwita I. 2010. Penentuan Status Mutu Air Kali Surabaya dengan Metode Storet dan Indeks Pencemaran. Majalah IImiah Widya. 27(297):59-63.

Taqwa, R.N., Muskananfola, M.R., Ruswahyuni. 2014. Studi Hubungan Substrat Dasar dan Kandungan Bahan 
Organik dalam Sedimen dengan Kelimpahan Hewan Makrobenthos di Muara Sungai Sayung Kabupaten Demak. DIPONEGORO JOURNAL OF MAQUARES. 3(1): 125-133.
Valentina, A.E., Miswadi, S.S., Latifah. 2013. Pemanfaatan Arang Eceng Gondok dalam Menurunkan Kekeruhan, COD, BOD pada Air Sumur. Indonesian Journal of Chemical Science. 2(2):8589. 